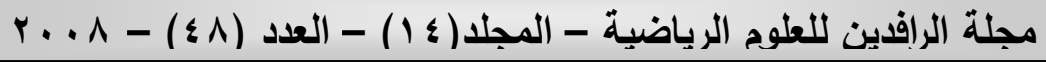

أنماط التفكير الاستراتيجي لاى مشرفي التربية الرياضية في

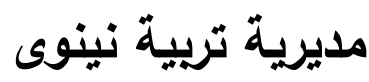

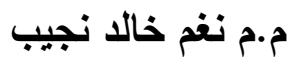

جامعة الموصل /كلية التربية الرياضية

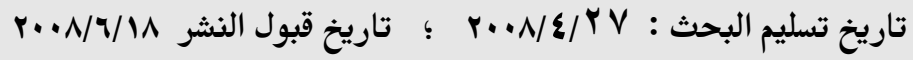

\begin{abstract}
الملخص
هدف البحث إلى التعرف على درجة أنماط التفكير الاستراتيجي لدى مشرفي التربية

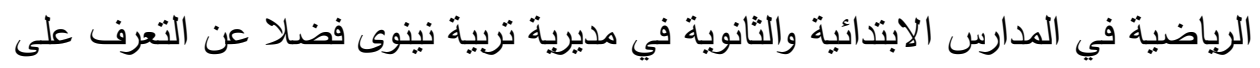

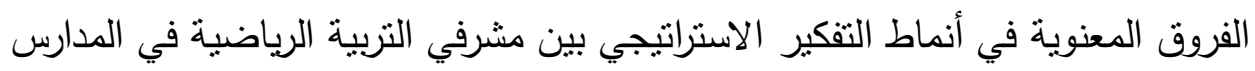
الابتدائية والثانوية في مديرية تربية نينوى ، وللتحقق من ذلك افترضت الباحثة فرضتنين

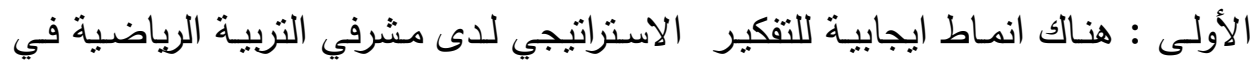

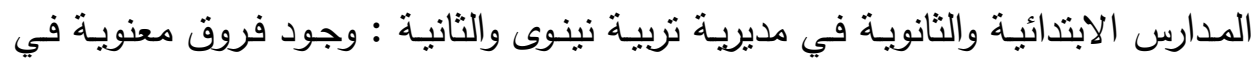
أنماط التفكير الاستراتيجي لاى مشرفي التربية الرياضية في الددارس الابتدائية والثانوية في مديرية نربية نينوى •

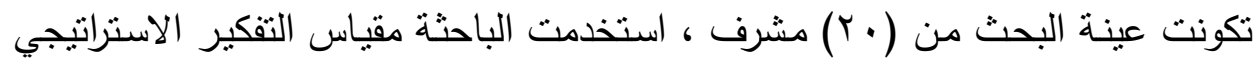

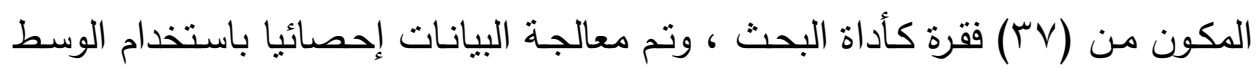

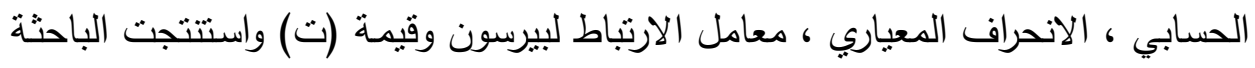

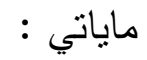
1- انخفاض درجة استخدام أنماط التفكير التخطيطي والثنمولي والتشخيصي r-وجود درجة استخدام منوسطة في التفكير التجريدي ץ-وجود فرق معنوي في التفكير التشخيصي بين مشرفي التربية الرياضية في المدارس الابتدائية والثانوية ولصالح مشرفي المدارس الابتدائية
\end{abstract}




\section{Abstract \\ Modes of Strategic Thought for the Physical \\ Education Supervisors in the Nineivah \\ Education Office}

\section{Nagham Khalid Nageb \\ University of mosul/College of Physical Education}

The aim of this research is to recognize the degree of strategic thought modes for physical education supervisors, in the secondary and primary schools in Nineivah education office . Also, it aimed to recognize the moral difference in the strategic thought modes, among physical education SUPERVISORS in the primary and secondary schools in Nineivah education office. And to investigate that, the researcher hypothesized two hypo thesis's : firstly, the positivety of the strategic thought modes for the physical education supervisors, in the primary and secondary schools, in the physical education office . Secondly, the researcher believed that, they had moral differences in the strategic thought modes among the physical education supervisors in primary and secondary schools in Nineivah education office. The sample of the research consists of (20) supervisors, and the researcher used the strategic thought scale which consists of (37) items as a research device, and the data were treated statistically by using the mathematical mean, standard deviation, correlation coefficient of person and ( $\mathrm{t}$ ) value the researcher concluded the following :

1- Reducing of the degree of using modes of thinking , planning, completing, and diagnosing .

2- Existence of the middle degree in using of divestment thinking .

3- Existence of moral distinction in diagnosing thinking between the supervisors of primary and secondary school, for primary school supervisors . 


\section{التعريف بالبحث}

\section{1 - المقدمة وأهمية البحث}

تعد التربية قطاعا من القطاعات الواسعة التي شهدت وتشهد تحولات سريعة تتطلب

دراسة متغيراتها العديدة والمنرابطة والتي قد تؤثر في مسيرة هذه التحولات وتحقيق أهدافها،

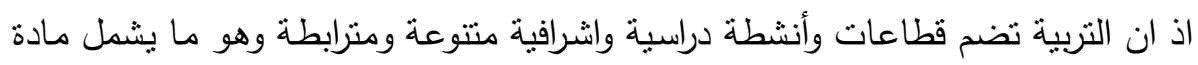

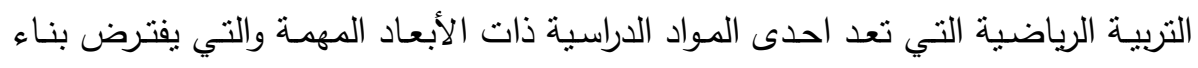
عليها ان يزداد اهنمام ذوي العلاقة بها تخطيطا وتدريسا وأثرافا ـ ولقد ارتأت الباحثة نتاول احدى هذه العمليات متمنلة بالأشراف التربوي وبالتحديد المشرفين التربوبين اختصاص دهاص التربية الرياضية والذين يتوجب عليهم العدل بنسق جديد لمواجهة التحديات التي نواجه المنظمات التربوية والتي من بينها أيجاد حالات التكيف والتلاؤم مع التحولات ومعطياتها والتي تضيف اليهم مهام جديدة في تحريك موارد أنشطتهم وتحقيق أهداف عالية المستوى

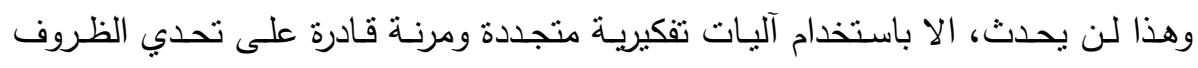
الصعبة والمعقدة التي تمر بها منظماتتا التربوية وبالتحديد مدارسنا.

وعليـه يـرى العديد مـن البـاحثين ان الادارة الاسـتراتيجية بوصفها فكـرا ومضمونا وسـلوكا وتوجها هي احدى الوسائل الفعالة لانقاذ المنظمات من حالات الفشل والانهيار فهي تسمح بالتقييم المستمر للتغيير في الظروف البيئية الداخلية والخارجية وتحديد الامكانيات الملائمة

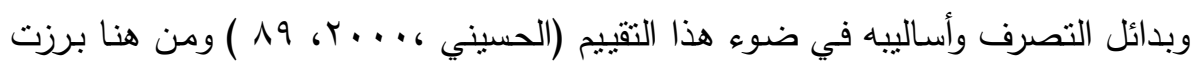

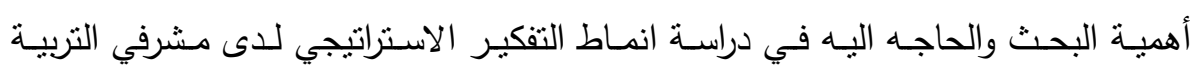
الرياضية في المدارس الابتدائية والثانوية في مديرية تربية محافظة نينوى .

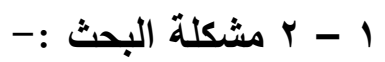

أن تقدم أية امة من الأمم يتأثز الى حد بعيد بمدى النطور العلمي والتكنولوجي الذي تحرزه تللك الأمة، وان هذا التطور الذي تصل اليه يعكس هو الآخر مدى كفاءة وفاعلية انظمتها التربويـة وسياستها التعليميـة، فالعصر الحالي هو عصر تغير دائم ولابـد فيـه للمنظمات

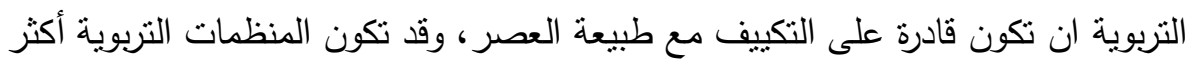
حاجة لمسايرة الواقع نظرا لطبيعة أهدافها ودورها وبذلك فهي أكثر حاجة من المنظمات الأخرى لملاكات بشرية متخصصة وملائمة ومن هذه الملاكات المشرفين التربوبين والذين

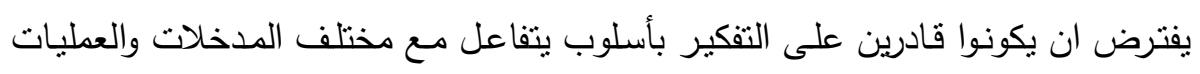

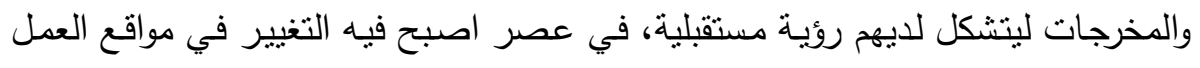

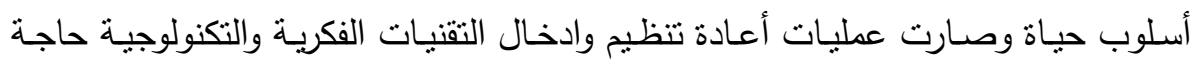


يجب ان تكون متوافرة لديهم وان تكون اتجاهـاتهم نحوها ايجابية، فعصر الثورة المعرفية والتكنولوجيـة يتطلـب مسشرفين يختلفون في تفكيـرهم، مـن هنـا تكتسب مسشكلة البحـث

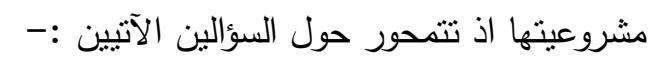
- مـا درجـة ممارسـة أنماط التفكير الاستراتيجي لدى المشرفين التربوبين في اختصاص الاص

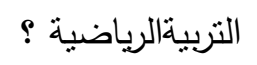

- هل هناك فروق معنوية في أنماط التفكير الاستراتيجي بين مشرفي التربية الرياضية في المدارس الابنذائية والثانوية في محافظة نينوى ؟ هنوبه

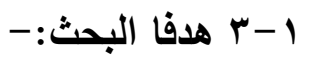
يهدف البحث إلى التعرف على : * درجـة أنماط التفكير الاستراتيجي لدى مشرفي التربية الرياضية في المدارس الابتدائية والثانوية في مديرية تربية محافظة نبنوى •

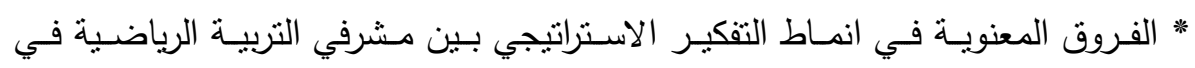
المدارس الابتدائية والثانوية في مديرية تربية محافظة نينوى .

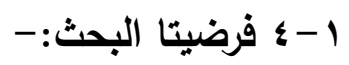
* هناك انماط ايجابية للتفكير الاستراتيجي لدى مشرفي التربية الرياضية في المدارس الابتدائية والثانوية في مديرية تربية محافظة نينوى • * وجود فروق معنوية في انماط التقكير الاستراتيجي بين مشرفي التربية الرياضية في المدارس الابتدائية والثانوية في مديرية تربية محافظة نينوى .

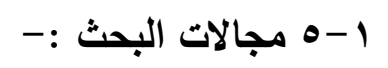
* المجـال البشري :مسشرفو التربيـة في اختصـاص التربيـة الرياضـية في المـارس الابتدائيـة والثانوية في مديرية تربية محافظة نينوى

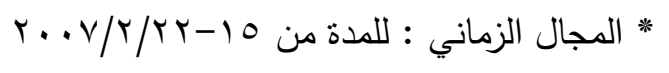

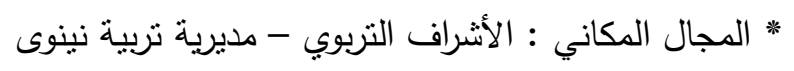
1-7 تحديا المصطلحات :-

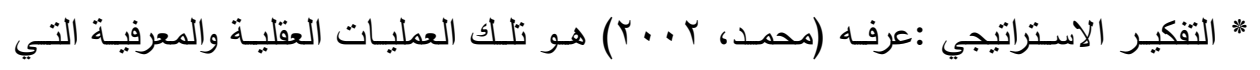
يستخدمها الفرد لحظة النظر الى المشكلات التي تسنوجب اتخاذ قرارات، ويتطلب التعامل مـع

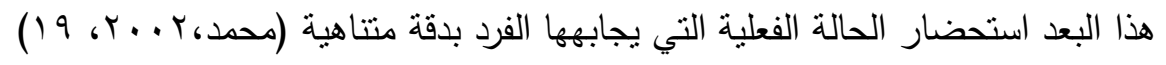

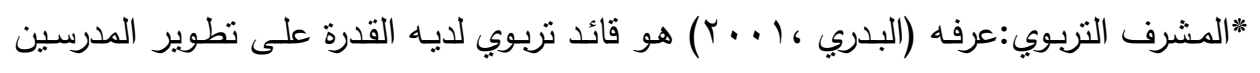
والمعلمين وتتميـة قدراتهم وتلبيـة وتحقيـق ميـولهم الخاصـة ومساعدتهم في المنـاهج والبـرامج واطلاعهم على احدث طرق التدريس واختيار المناسب منها (البدري ، ( . . ب ، . ع) 
* الأثـراف النربوي : عرفه (قطب،وآخران ،ع 1911 ) هي الجهة التي تتعهد بتوجيه العطلية التزبوية وترشيدها من خلال تقويم عناصر هذه العملية وتطوير العاملين ومساعدتهم على حل

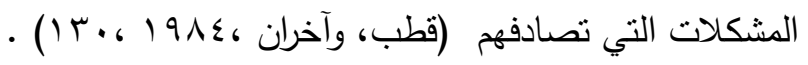
r- الاطار النظري والدراسات السابقة

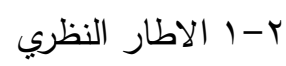

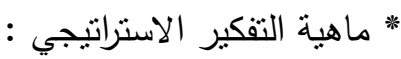
يعد التفكير الاستراتيجي مسار فكري محدد لله خط سير خاص بهاه يريح العقل من عناء تنقية الافكار المتشابكة من الثوائب والتطورات التي لايحتاجها الذهن اثتاء

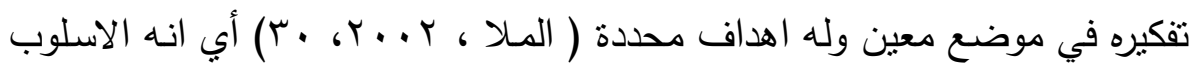
الذي يمكن من خلاله المسؤولون من توجيه المنظمة بداية من الانتقال من العمليات

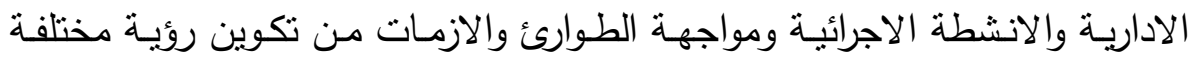

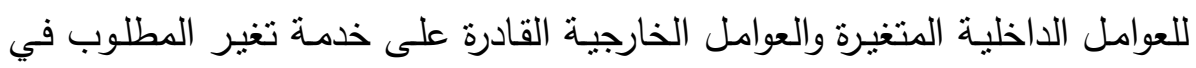
البيئة المحيطة باولئك المسؤولين بمـا يتضمن في النهايـة افضل استخدام ممكن

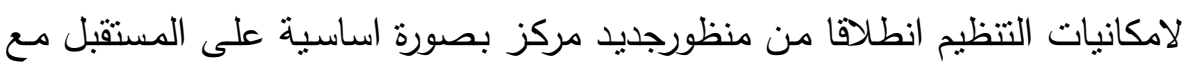

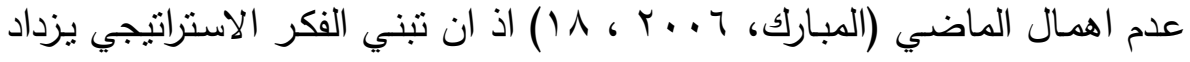
بزيادة عدد المستويات الادارية وزيادة معدلات التغير البيئي وارتفاع معدلات مخاطر

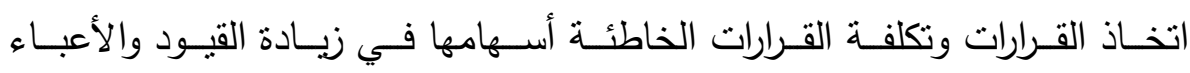

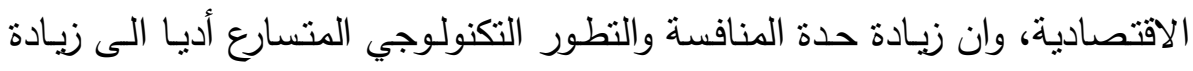
معدلات تبني التفكير الاستراتيجي مـن الأفراد ليتمكنوا مـن الحفـاظ على القدرة

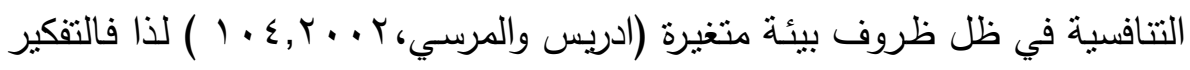
الاسـتراتيجي هـو الذي ينطوي على نحريك الواقـع على وفق معطيـات المبـادأة والابتكار الذي يخرج في الأغلب عن السياق المألوف ( Liedtka 1998,120) . * المبادى الاساسية التي يقوم عليها التفكير الاستراتيجي الفاعل : 1- التفكير الاستراتيجي يتطلب التزام من القيادة . r- التفكير الاستراتيجي وسيلة وليس غاية. r- التفكير الاستراتجي عملية دينامكية مرنة . ع - التفكير الاستراتيجي يتطلب توسيع المشاركة.

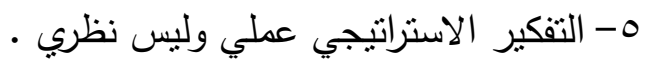

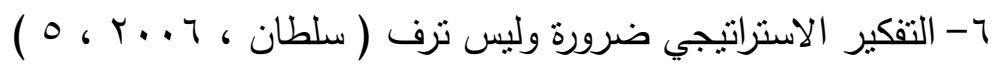
* مزايا التفكير الاستراتيجي : 


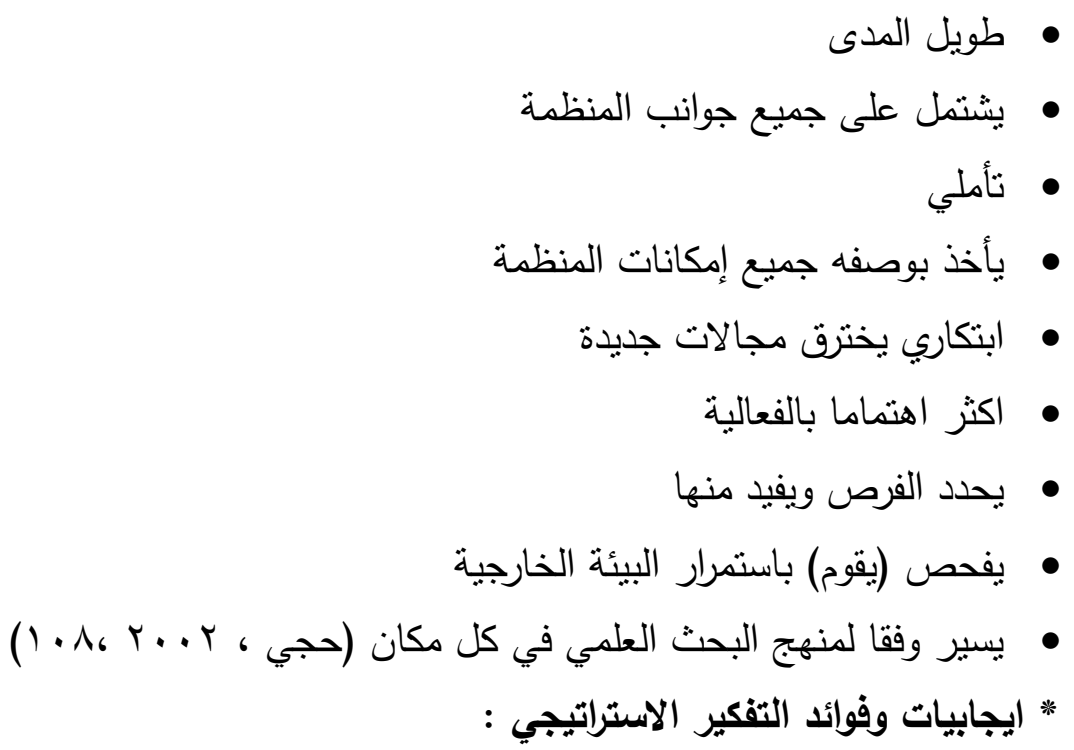

بلورة الاطار الفكري للنظر الى المنظمة في محيطها الكلي وعلاقاتها الشمولية

بدلا من وصفها صندوقا مغلقا لا يؤثرولا يتاثز

ه توصيد الجهود وتعبئة الطاقات نحو الاهداف والغايات بدلا من تركيزها على

الوسائل والجزبئات

يعزز ثقة الافراد والجماعات والمنظمات بذاتها وبهويتها ويوحد كلمتها ويبعث

في النفوس الأمل ويشعرها بقدرتها على المساهمة في صنع مستقبلها والمفاضلة

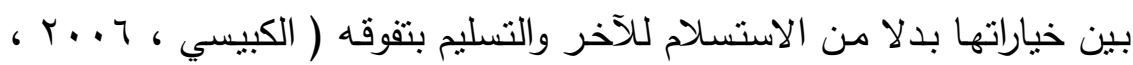

( I t

* أنماط التفكير الاستراتيجي :

تتعدد انمـاط التفكير بتعدد المواقف التي يجابهرا متخذ القرار وفقا لأسـاليب اختيارهم

البدائل الاستراتيجية، وفي ضوء ذلك تقسم الى أربعة انماط :

اولا: التفكير الشامل :-

في هذه النمط من التفكير يهتم الفرد الاستراتيجي بتحديد الاطسار العام للمشكلة

اعتمادا على الخبرة المتراكمة في تحديد أولويات العوامل المؤثرة في المشكلة، فضلا عن صياغة اطر النتائج المستهدفة ( Lyles\&Thomas , 1988,131 ) وهذين الاهتمامين مـن القائد الاسـتراتيجي يولدان سـرعة الاستجابة لوضـع الحلـول التي تعتمد دقتهاعلى المهـارات العقليـة للقائـد فـي فهم واسـتيعاب الموقـف ومــا ينـتج عنـه مـن علاقـات

(احتمالية)(Hickson, 1987,165)

وفي هذا النمط التفكيري يقرن القائد نجاح قراراته بمظاهر الابداع والخيال التي تنعكس

بشكل واضح على تصميم الأنشطة والممارسات المنظمية ( Mason,1988,27 ) 
ثانيا: التفكير التجريدي :-

في هذا النمط من التفكير يهنم القائد بحصر العوامل العامة المحيطة بالمشكلة في اطار

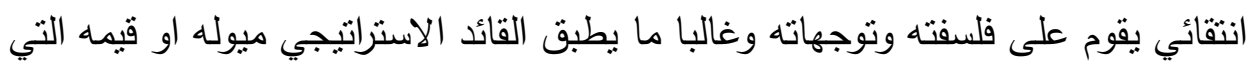

تتحدد في ضوء حسه او خياله لهذا الصدد (Hamal\&Prahalad,1989,63)

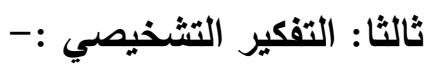

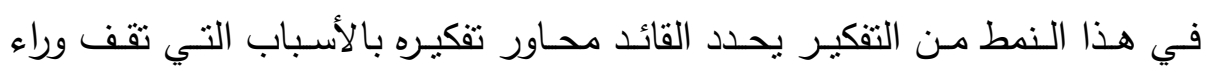
المشكلة، اذ يعتمد على قانون السبية في التحليل والتحقق من قوة العلاقة ومعنوياتها،

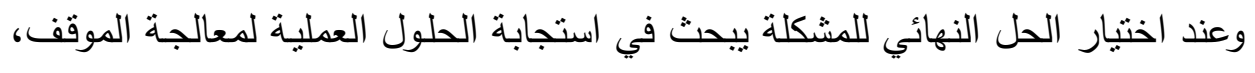

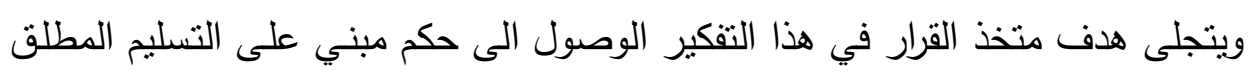

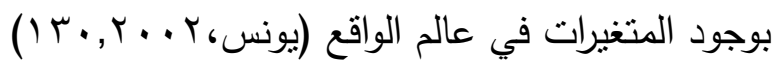
رابعا: التفكير التخطيطي :-

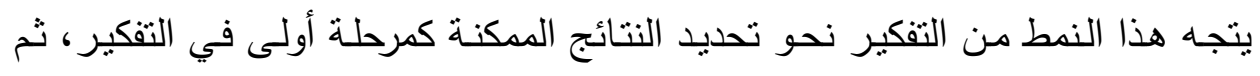

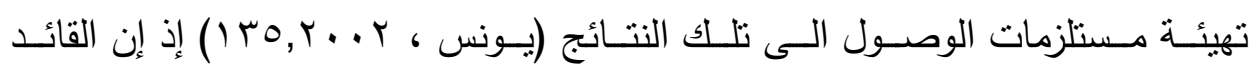
الاستراتيجي يركز في هذا النمط بشكل اقل على حتمية توافر جميع الأسباب الكامنة

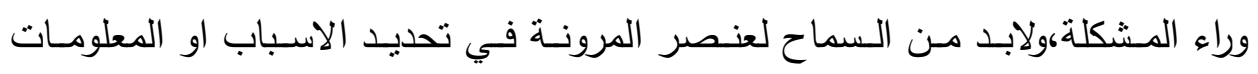

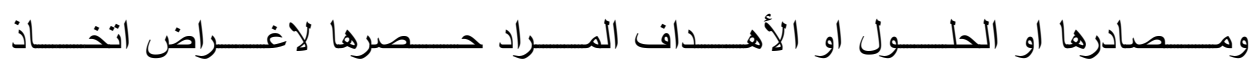

القرار (Hamal\&Prahalad,1989,66) r-r الدراسات السابقة :

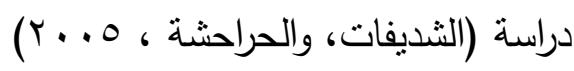

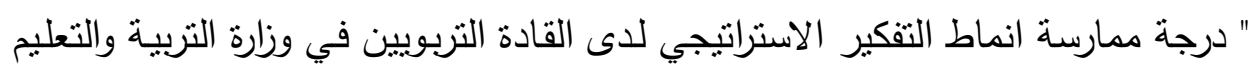
في الاردن " هدفت الدراسة الى التعرف على درجة ممارسة انماط التفكير الاستراتيجي

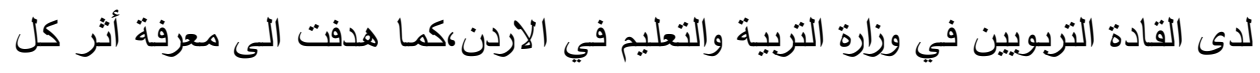

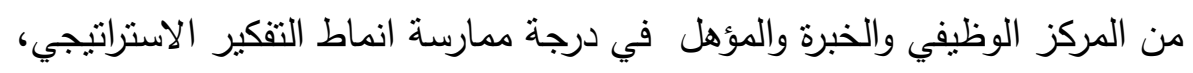

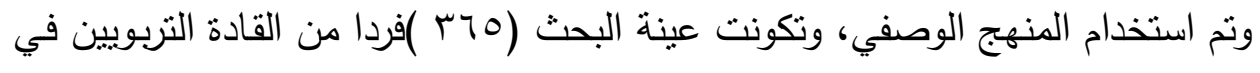
وزارة التربية والتعليم العالي في الاردن، واستخداما ( الوسط الحسابي، الانحراف المعياري

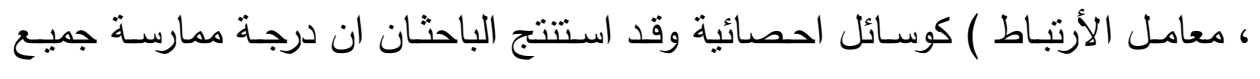
)

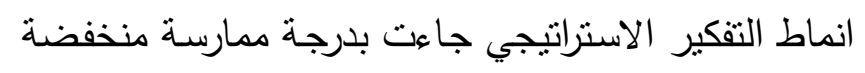

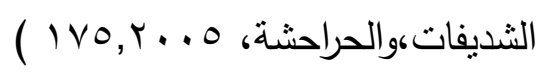




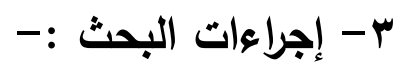
rاستخدمت الباحثة المنهج الوصفي بطريقة المسح لملائمته لطبيعة البحث . r-r عينة البحث تم اختيـار عينـة البحث بالطريقـة العمديـة مـن المشرفين التربوبين للمدارس الابتدائيـة والثانويـة في اختصاص التربيـة الرياضية في الاشـراف التربوي التابع لمديريـة تربيـة

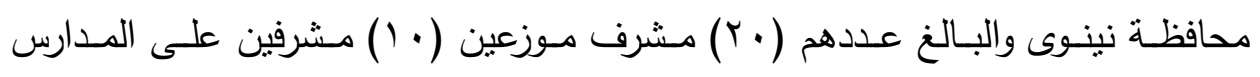

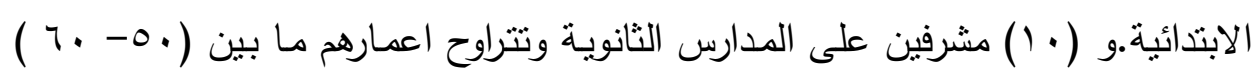

سنة . r-r ب أداة البحث

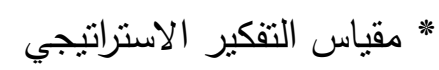
اعتمدت الباحثة المقياس الذي أعده (يحيى محمد الثديفات ومحمد عبود الحراحشة )

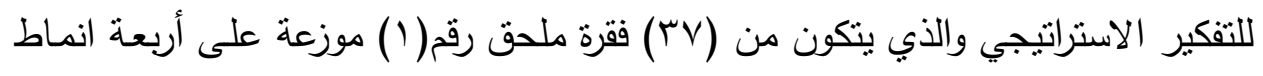
هي التفكير الشمولي ويضم (^) فقرات، والتفكير التجريدي ويضم (1) (1) فقرة والتفكير

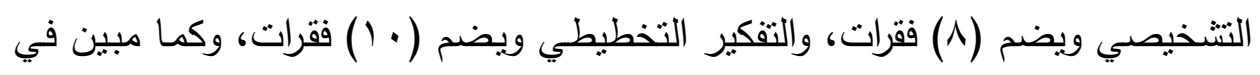

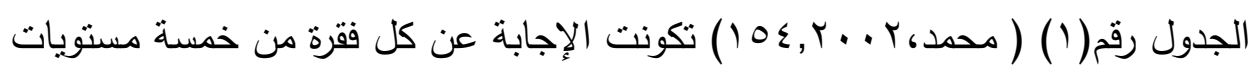

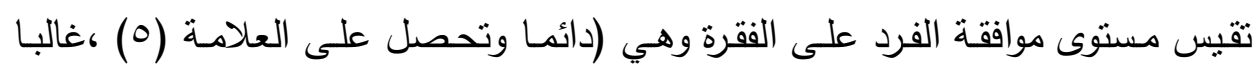

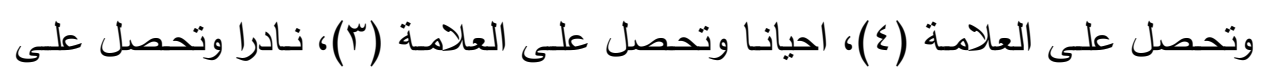

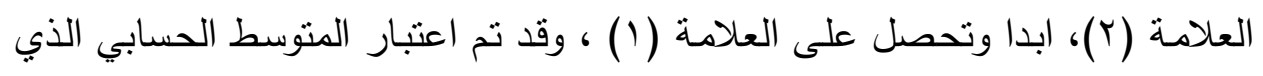

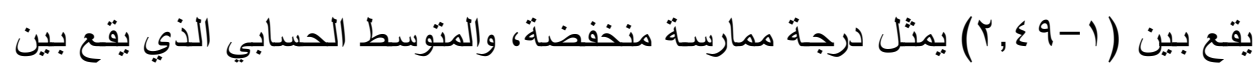

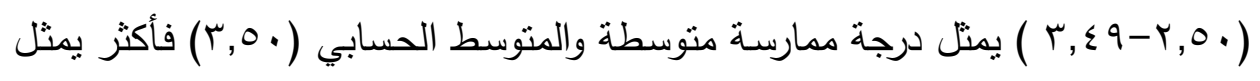

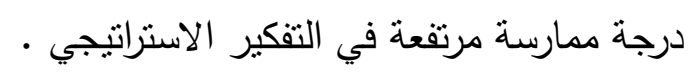

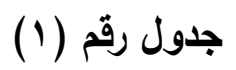

يبين توزيع مفردات استبانة التفكير الاستراتيجي حسب الأنماط وعدد الفقرات في كل نمط 


\begin{tabular}{|c|c|c|c|}
\hline عدد الفقرات & رقم الفقرات & 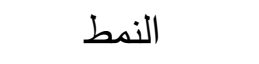 & 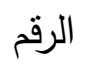 \\
\hline$\wedge$ & ( $Y q, r 0, r), 1 \vee, 1 r, q, 0,1$ & التفكير الشمولي & 1 \\
\hline 11 & $r \vee, r \diamond, r r, r \cdot, r \tau, r r, 1 \wedge, 1 \leq, 1 \cdot, T, r$ & التفكير التجربدي & r \\
\hline$\wedge$ & $r, r V, r r, 19,10,11, V, r$ & التفكيرالتشخيصي & r \\
\hline 1. & $\Gamma\urcorner, \Gamma \varepsilon, \Gamma Y, Y \wedge, Y \varepsilon, Y \cdot,|\neg| r,, \wedge, \varepsilon$ & التفكيرالتخطيطي & $\varepsilon$ \\
\hline
\end{tabular}

يعد الصدق " أهم شروط الاختبار الجيد فالاختبار الصادق هو الذي ينجح في مقياس ما وضع من اجله " (حسانين ،990, 99 (1) ) ولغرض التأكد من صدق المقياس قامت الباحثة بعرضه على مجموعة من السادة الخبراء* 'والمختصين في مجال الادارة التربوية الرياضية والعلوم النفسية للتأكد من صـلاحية المقياس لهذا الغرض وتم استخدام النسب المئوية معيارا حول مدى صدق المقياس للغرض الذي وضع من اجله، اذا اتققت أراء

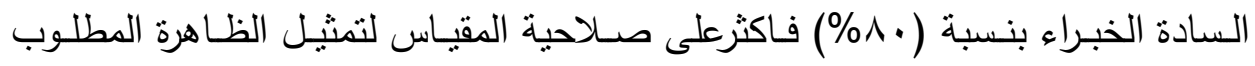

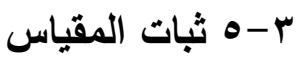

يقصد بالثبات " الاستقرار بمعنى انه لو كررت عمليات قياس الفرد الواحد لبينت درجته شيئا من الاستقرار ومعامل الثبات هو معامل ارتباط بين درجات الأفراد في الاختبار في

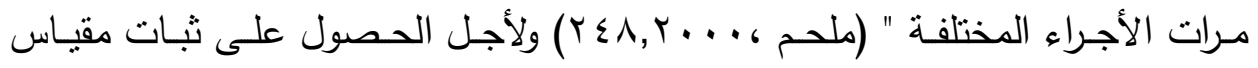
التفكير الاستراتيجي استخدمت الباحثة طريقة اعادة التطبيق وذلك من خـلال تطبيق المقياس على (T) مشرفين من الاثراف التربوي، واعيد توزيع المقياس مرة ثانية بعد مرور اسبوعين وبعد جمع الاستمارات تمت معالجتها إحصائيا باستخدام معامل الارتباط البسيط (بيرسون) فظهرت قيمة (ر) المحتسبة (سی, • ) وهذا بدل على ارتباط عالٍ، ومن ثم يؤكد ان المقياس يتمتع بمعامل ثبات عال •

كلية كلية التربية الرياضية




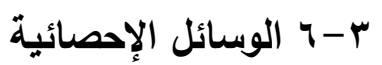

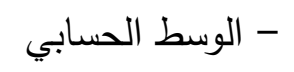

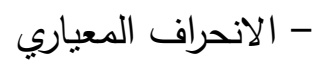

- اختبار ( T ) للعينات المستقلة

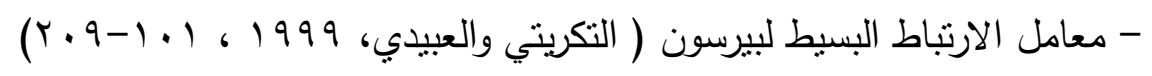

$$
\text { ع - عرض ومناقثة النتائج :- }
$$

بعد جمع البيانات التي حصلت عليها الباحثة وللتحقق من صحة فرضيتي البحث

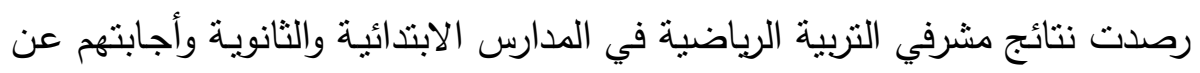
كل نمط من انماط التفكير الاستراتيجي، ثم تم تحليل البيانات إحصائيا باستخدام

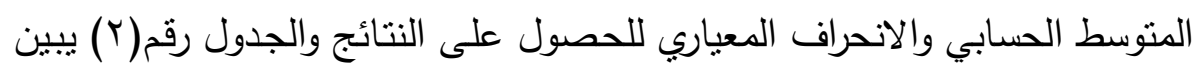

ذلك

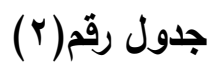

\begin{tabular}{|c|c|c|c|c|}
\hline درجة الممارسة & الانحراف المعياري & المتوسط الحسابي & نمط التفكير & الرتبة \\
\hline متوسطة & $\cdot, 70$ & $r, v r$ & تجريدي & 1 \\
\hline منخفضة & $\cdot, 90$ & $r, \varepsilon V$ & تخطيطي & r \\
\hline منخفضة & $\cdot, \wedge 7$ & Y, r & شمولي & $r$ \\
\hline منخفضة & $\cdot$, Vo & $r, 19$ & تشخيصي & $\varepsilon$ \\
\hline
\end{tabular}

\section{يبين المتوسطات الحسابية والانحرافات المعيارية والدرجة التي تمثل إجابات عينة} الدراسة عن كل نمط من انماط التفكير الاستراتيجي مرتبة تنازليا

ويتبين من الجدول رقم(r) انخفاض استخدام انماط التفكير التخطيطي والثمولي

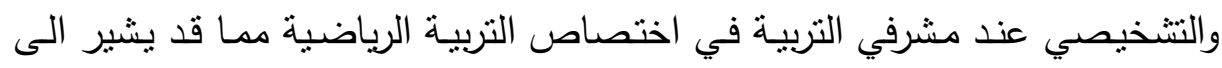

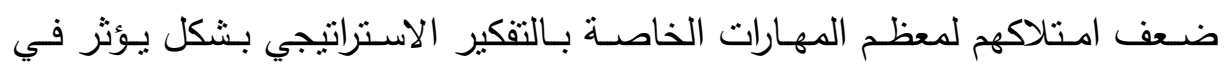

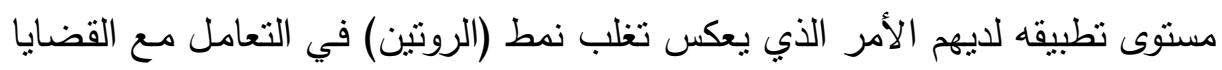

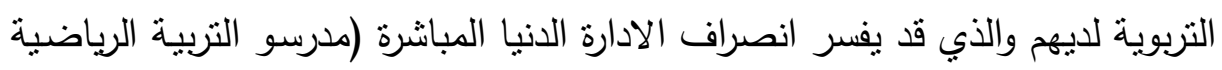

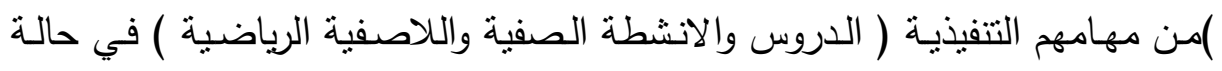

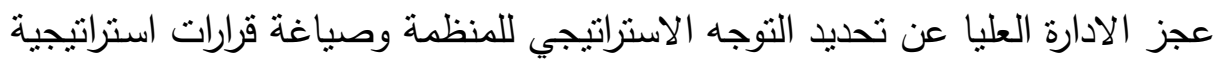

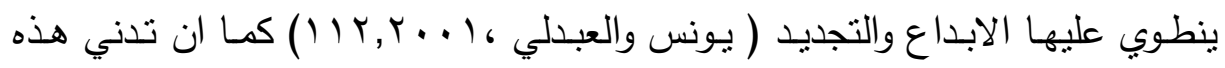


الأنماط الثلاثة قد يفهم منه ان هذه القيادات مازالت تتبع تعليمات وتوجيهات مفروضة

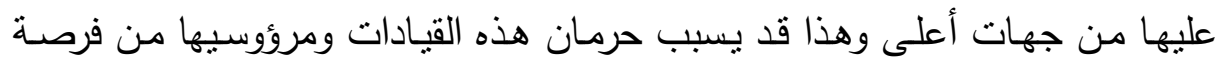
ممارسة مهارات التفكير الاستراتيجي التربوي بشكله الحقيقي والايجابي • وقد يفسر حصول نمط التفكير التجريدي على درجة ممارسة متوسطة على الرغم من انه يتمحور حول الاطار الانتقائي لحصر العوامل المحيطة بالمشكلة بناء على لهى فلسفتهم وتوجهاتهم التي تحدد في ضوء حسسهم او خيالهم فهم قد فهموا المشكلات التي تواجه النشاط الرياضي وحلولها ضمن اطارالحس والذي يشكل فيه الاحساس

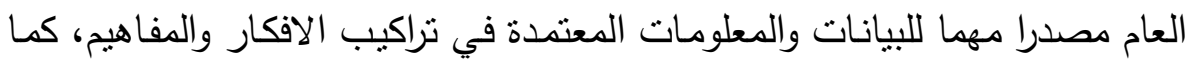

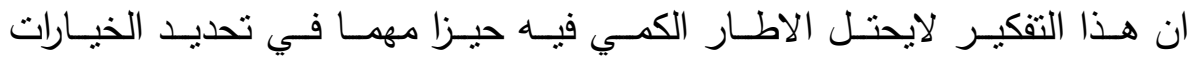
(Hamal\&Prahalad,1989,68)

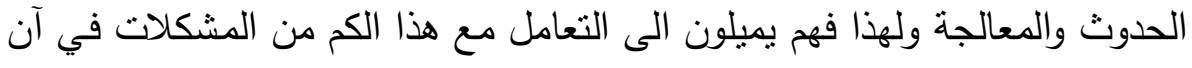
واحد وفق تفكير مجرد على أسس التراكم المعرفي (وهو ما موجود لليهم من جراء الممارسة والتعليم والتعلم ) ويكون القرار بمثابة استجابة للوضع الانتقائي الصادر عن الهيمنة الفكرية للقائد . وتعتقد الباحثة ان انخفاض نمط التفكير الشمولي قد يكون ناتجا عن الارتفاع الملحوظ في التفكير التجريدي القائم على الاحساس العام بصعوبة حل المشكلة مما

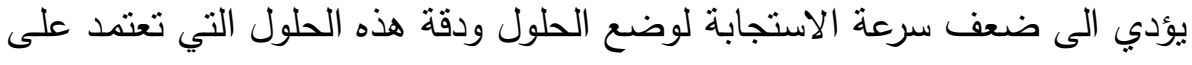
الههارات العقلية للقائد في فهم واستيعاب الموقف وما ينتج عنه من علاقات احتمالية وهذه المهارات العقلية غالبا ما تعتمد في تحليلاتها على انتقاء الحالات ويكون القرار بمثابة استجابة للوضع الانتقائي الصادر عن الهيمنة الفكرية للقائد وهذا يولد قلـة لفالة

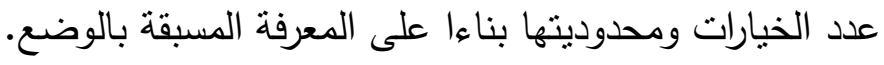

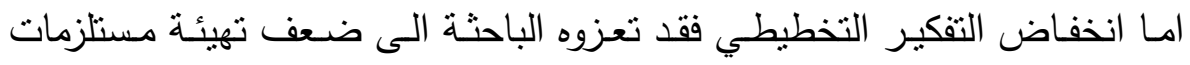
الوصول الى النتائج المخطط لها مما يؤثر في هذا النوع من التفكير، كما انه ربما

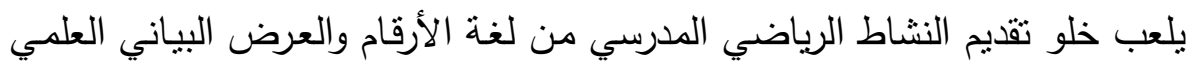

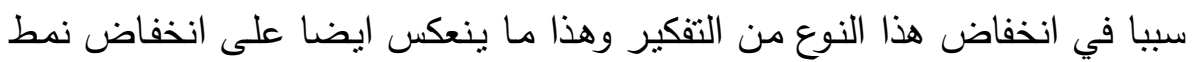

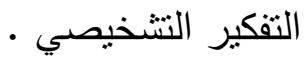
إذا إن هذين النمطين التشخيصي والتخطيطي يتفقان في السياقات العامسة في التفكير ومنها التعامل مع الموضوعات او المشكلات التي تخضع الى لغة الأرقام

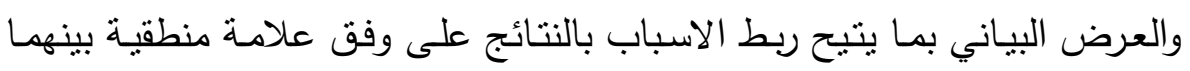


جدول رقم(")

يبين قيم (ت) المحسوية بين مشرفي الابتدائية ومشرفي الثانوية

\begin{tabular}{|c|c|c|c|c|c|c|}
\hline \multirow{2}{*}{ الدلاله } & \multirow{2}{*}{ المحسمبة (ت) } & \multicolumn{2}{|c|}{ مشرفو الثانوية } & \multicolumn{2}{|c|}{ مشرفو الابتدائية } & \\
\hline & & $\varepsilon^{ \pm}$ & سَ & $\varepsilon \pm$ & 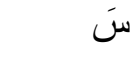 & \\
\hline غعنوي & 1.74 & 9.19 & rl.s. & 9.r. & r^.l. & تخطيطي \\
\hline غعني &. .10 & E.TV & 18.7. & $9 . .4$ & $1 \wedge .1$. & شمولي \\
\hline غعني & 1.97 & r.v. & TV.T. & A.V $\varepsilon$ & rr.l. & تجريدي \\
\hline معنوي & *Y. $\{Y$ & $r . r$ & $1 \leq . v$. & $v .19$ & $r \cdot .0$. & خيصي \\
\hline
\end{tabular}

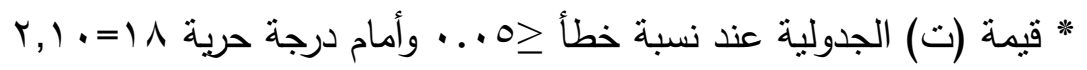

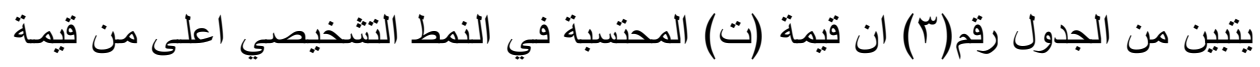

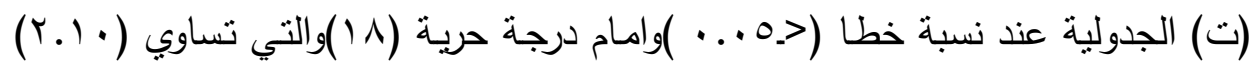
ويعود السبب في معنويـة الفروق بـين مشرفي الابتدائيـة والثنانويـة في نمط التفكير

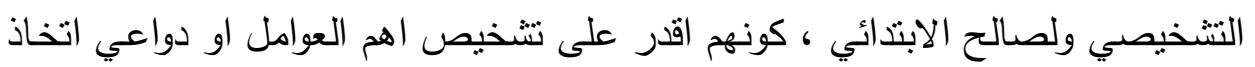

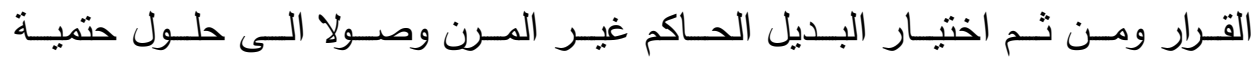
(Birnbaum,1984,489) التي تتص على ان سياقات اختيار البديل دون غيره من البدائل انما هو عملية تطابق بين الصورة التي تكونت في الاذهان مـع الواقع ( وكلاهما سلبي في مدارسنا ) وعند حصول هذا التوافق بين الصورة الذهنية ومعطيات الواقع يكون القرار اكثر دقة وتحديدا،

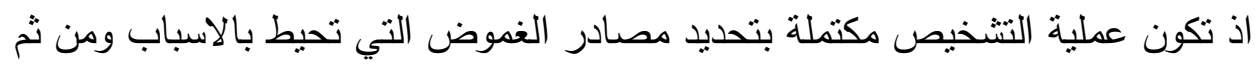

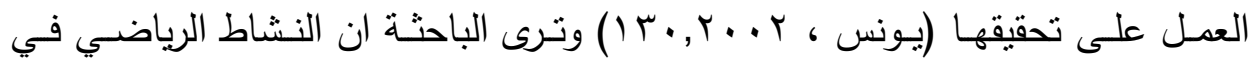
المدارس الابتدائية ربما يكون ذو سياسات او خطوط عريضة اكثر ثباتا من المدارس

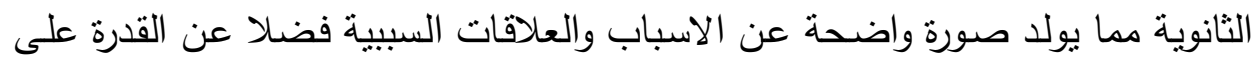


التتبؤ بالمحصلة التي تؤول اليها تلك العلاقات السبيية وتبوييها لغرض اختيار بدائل استراتيجية رئيسة وأخرى طارئة لدرء الدفاجأت حين حدوثها وهذا ما يمكن السيطرة عليه

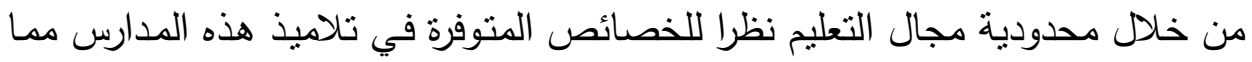
قد يفرض نشاطات رياضية واضحة المرامي والأهداف . ويمكن ان تعزو الباحثة الفروق في التفكير التتخيصي بين مشرفي الابتدائية والثانوية ربما الى اهتمام الددارس الابتدائية وقادتها ومشرفيها على زيادة تطوير رغبة التلاميذ في

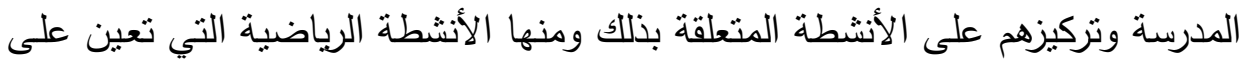

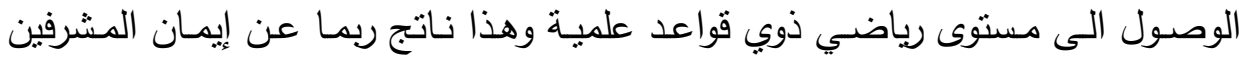
والمعلمين وإدارات المدارس الابتدائية من ان مسؤوليات الاثشراف لا تقتصر على زيارة المعلمين وتوجيهم بل تقويم العملية التربوية من خلال تشخيص اوجه النقص ومواطن

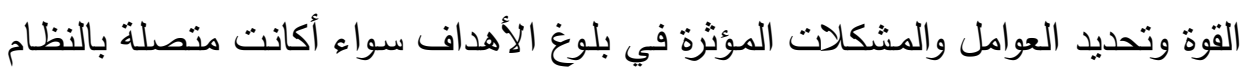

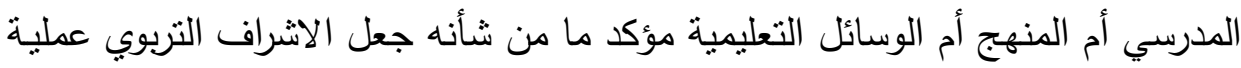

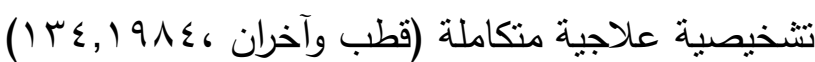

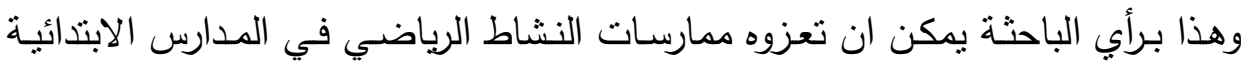

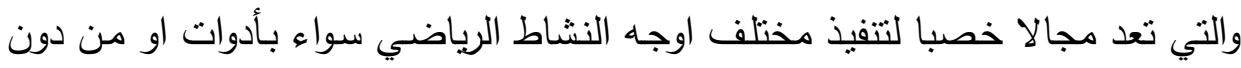
أدوات كالقصص الحركية والعاب السرعة والرشـاقة والألعاب الصغيرة ، بينما نجد ان

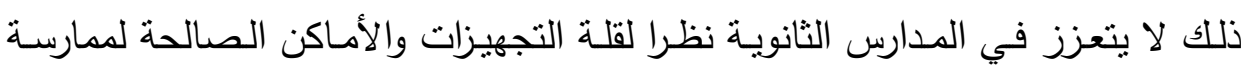

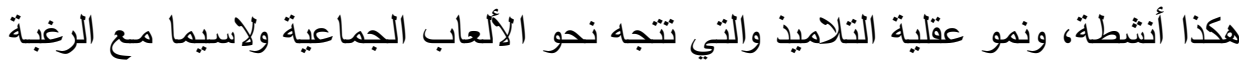

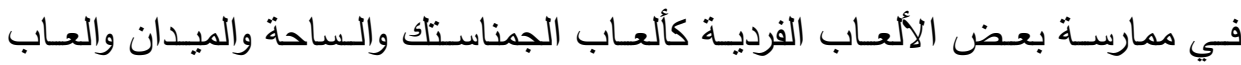
المضرب وهذا كله يحتاج الى تجهيزات وأدوات أساسية وملحقة ندرا وجودها في مدارسنا المتوسطة والاعدادية مما يؤثز على الاداء ومستويات التفكير بمشاكل هذا الأداء وقد يقود الى ركود مدرسي ومشرفي ومدراء هذه المدارس الى الرضـا بما هو موجود او دون ذلك ولهذا ربما يقتصر مسؤوليات الاشـراف التربوي في المدارس الثانوية على زيـارة

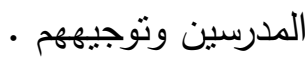

0- - الاستنتاجات والتوصيات

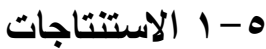

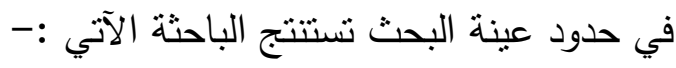
1- عدم فاعلية استخدام أنماط التفكير التخطيطي والثمولي والتئية والتشخيصي لاى مشرفي التربية الرياضية. 
r- هناك درجة استخدام منوسطة في التفكير التجريدي لدى مشرفي التربية الرياضية . r- وجود فرق معنوي في التفكير التتخيصي بين مشرفي المدارس الابتدائية والثانوية التية

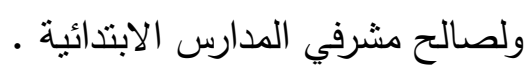

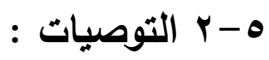

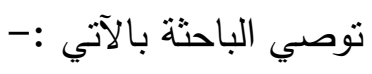

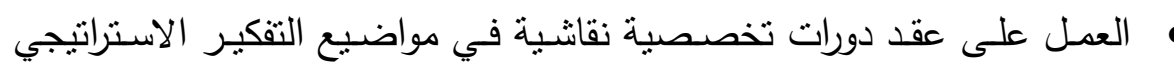

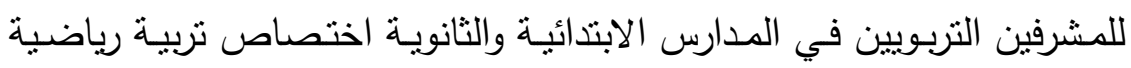

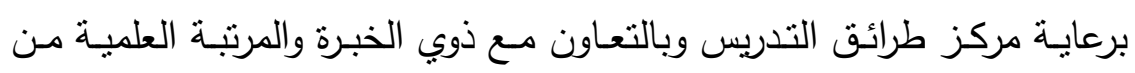

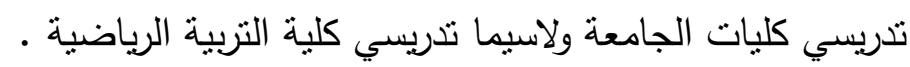

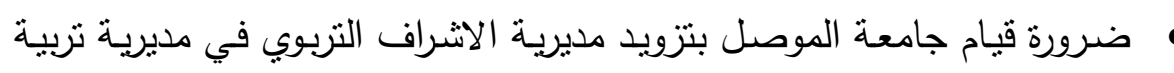
محافظة نينوى بالكتب والتقارير والبحوث ورسائل الماجستير واطاريح الدكتوراه

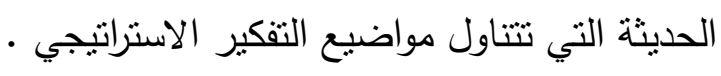

\section{المصادر}

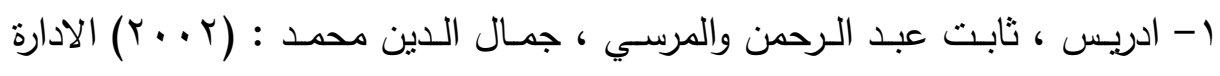

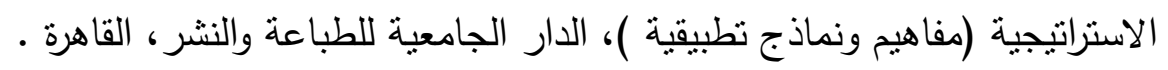

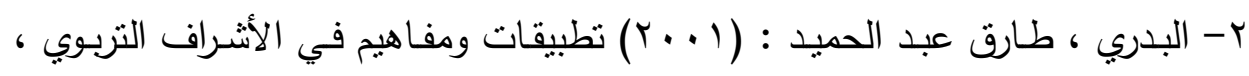

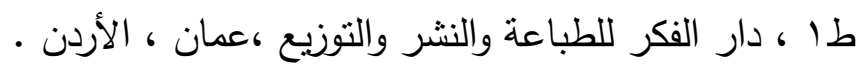

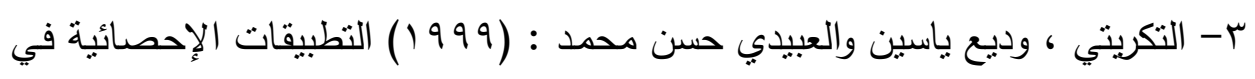

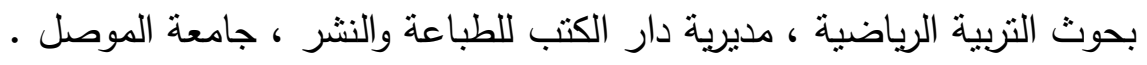

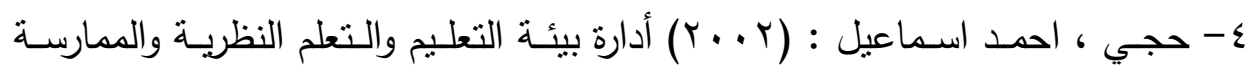
داخل الفصل والدرسة ، طا، دار الفكر العربي ، القاهرة

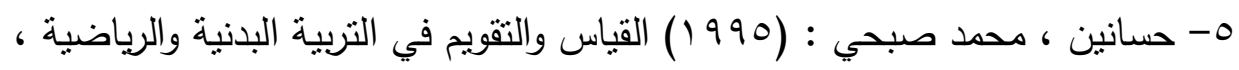
طب، ج ا، دار الفكر العربي للطباعة والنشر ، القاهرة

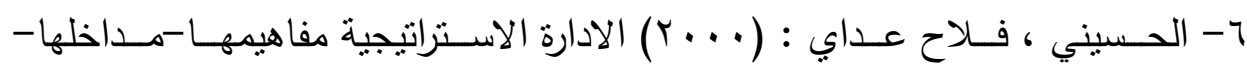

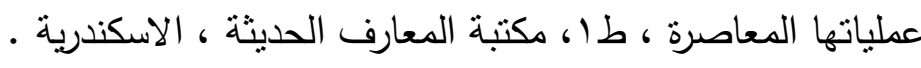

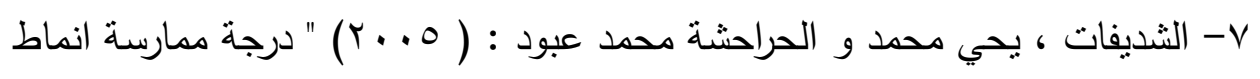

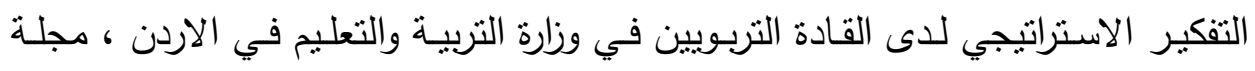

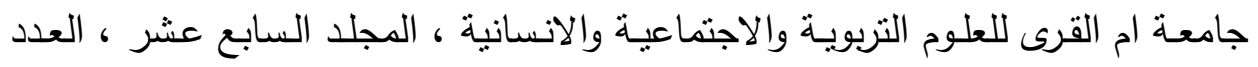




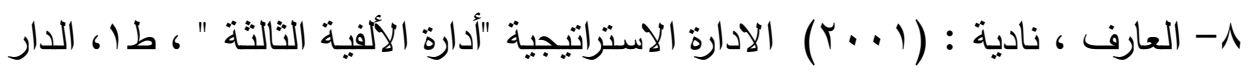
الجامعية ، القاهرة

9- قطب ، سعد محمد وآخران : (ع 9 (1) الادارة والتنظيم في مجال التربية الرياضية ،

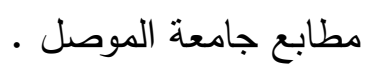

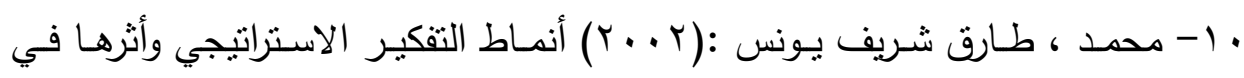

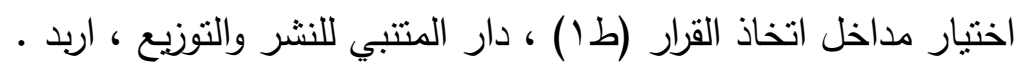

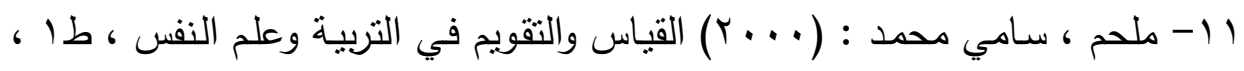

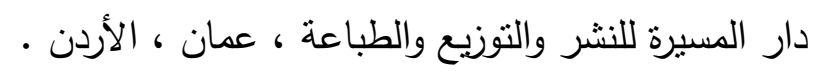

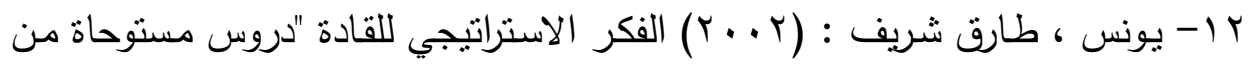
التجارب العالمية والعربية" ، طا ، المنظمة العربية للتمية الادارية ، القاهرة .

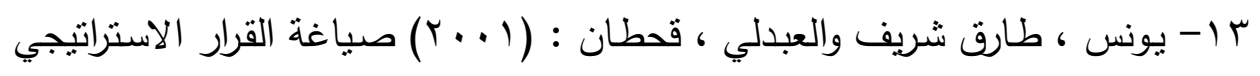

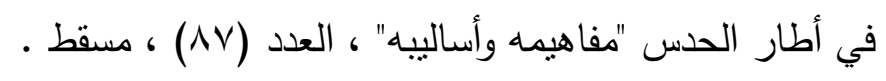
14- Birnbaum p.H (1984):"The choice of Strategic Alternatives Under Increasing Regulation in High Technology companies" Academy of Management Journal , Vol.27,NO.3 .

15- Farkas C.M.\& Wetlaufers (1996) :"The Way Chief Executive Officers Lead "Harvard Business Review.

16- HamaL Q \& Prahalad C.K (1989): " Strategic Intent " , Harvard Business Review , Vol. 67, NO.3.

17- Hickson, D.J.(1987):"Decision Making At The Top of organizations "Annual Reviews of Sociology . Vol.13,No.1. 18- Liedtka , j.M(1998) :"Strategic Thinking "Long Range Planning . Vol.31,No.1

19- Lyles M.A \& Thomas .j. (1988): " Strategic problem formulation : Biases and Assumptions Embedded in Alternative Decision Making Models" JournaL of Management studies , Vol25 , No.2.

20-

Mason,J.(1986): "Developing Strategic Thinking "Long 
Planning, Vol.19,No.3.

ملحق (1)

مقياس التفكير الاستراتيجي

\begin{tabular}{|c|c|c|c|c|c|c|}
\hline أبدا & نادرا & 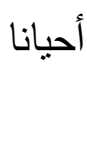 & غال & دائم & الفقرات & $ت$ \\
\hline & & & & & اعمل على إتاحة فرص تربوية متجددة & 1 \\
\hline & & & & & أفكر بالبديل الذي يعبر عن طموحاتي الذاتية & $r$ \\
\hline & & & & & أستثر الفرص التربوية المتاحة لأبناء المجتمع & $r$ \\
\hline
\end{tabular}




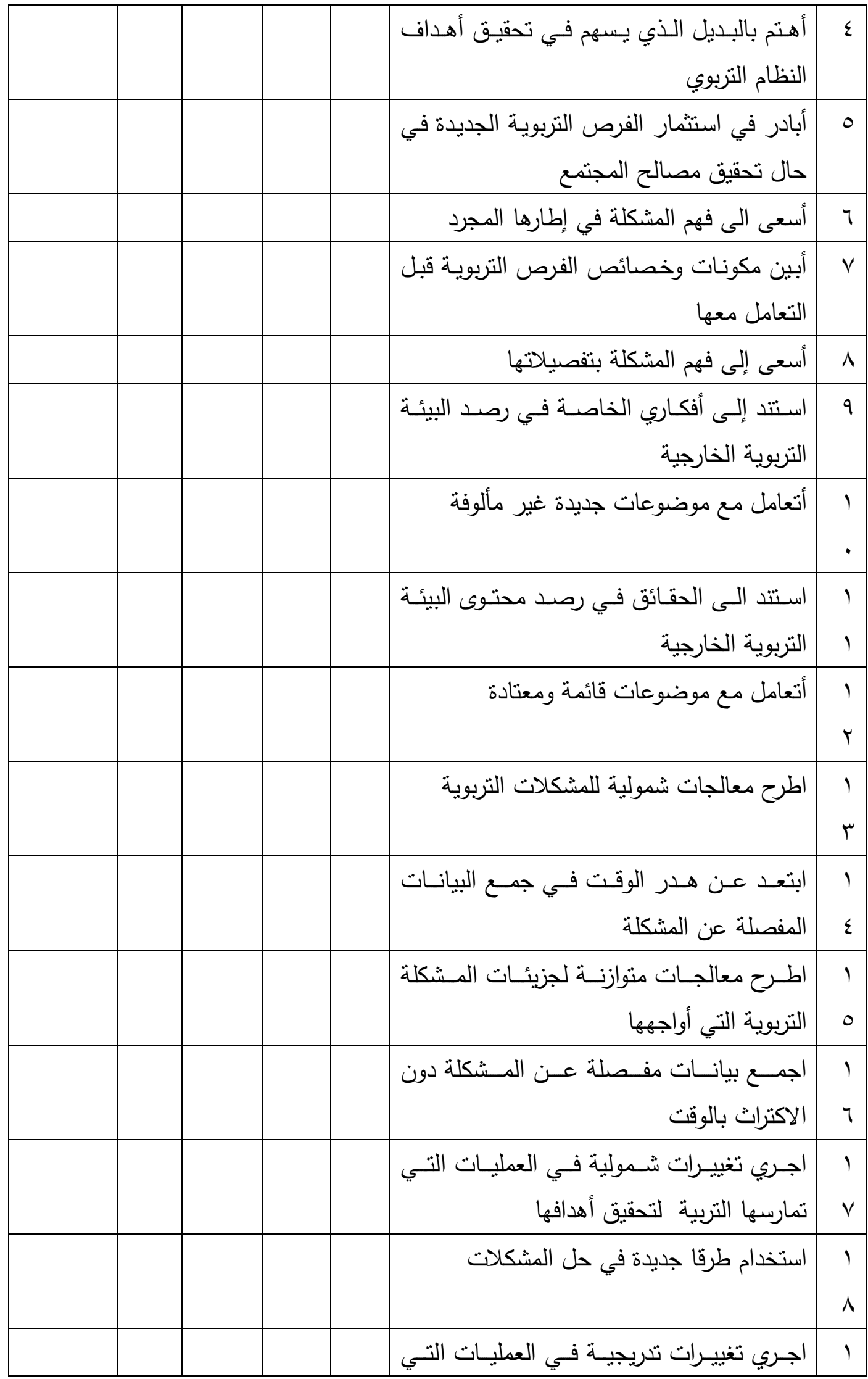




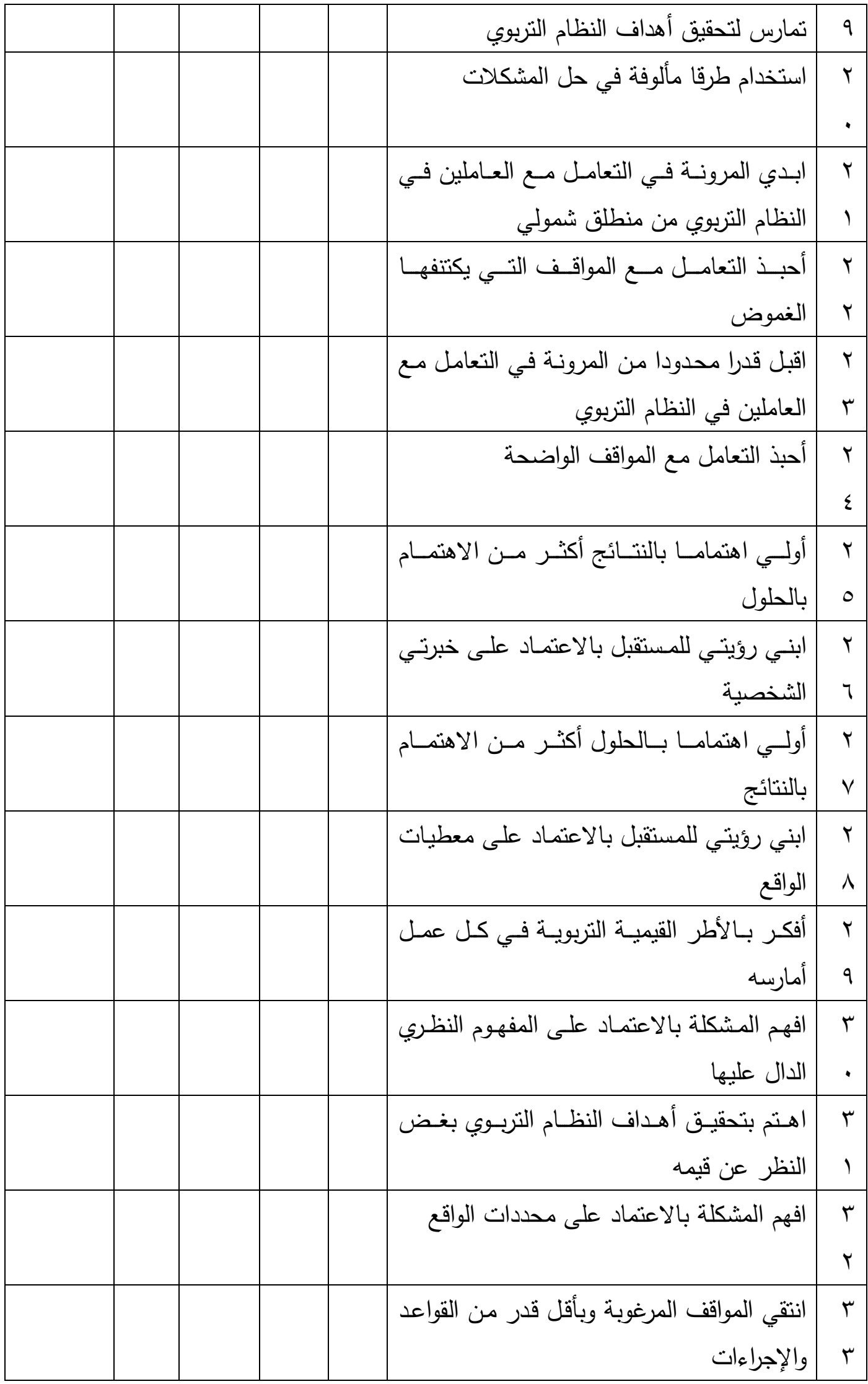




\begin{tabular}{|l|l|l|l|r|r|}
\multicolumn{2}{l|}{19} \\
\hline
\end{tabular}

